This item was submitted to Loughborough's Research Repository by the author.

Items in Figshare are protected by copyright, with all rights reserved, unless otherwise indicated.

\title{
Exploring the digital native assessment scale as an indicator for building more effective user experiences
}

PLEASE CITE THE PUBLISHED VERSION

https://doi.org/10.1007/978-3-030-60114-0_14

PUBLISHER

Springer

VERSION

AM (Accepted Manuscript)

PUBLISHER STATEMENT

The final authenticated version is available online at https://doi.org/10.1007/978-3-030-60114-0_14.

LICENCE

CC BY-NC-ND 4.0

\section{REPOSITORY RECORD}

Martin, Lexy, Steve Summerskill, Tracy Ross, Karl Proctor, and Arber Shabani. 2020. "Exploring the Digital Native Assessment Scale as an Indicator for Building More Effective User Experiences". Loughborough University. https://hdl.handle.net/2134/14141312.v1. 


\title{
Exploring the Digital Native Assessment Scale as an Indicator for Building More Effective User Experiences
}

\author{
Ms. Lexy Martin ${ }^{1}$, Dr. Steve Summerskill ${ }^{1}$, Dr. Tracy Ross ${ }^{1}$, Dr. Karl Proctor ${ }^{2}$, Dr. \\ Arber Shabani ${ }^{2}$ \\ ${ }^{1}$ Loughborough University, Loughborough, UK \\ ${ }^{2}$ Jaguar Land Rover, Coventry, UK \\ a.martinelboro.ac.uk
}

\begin{abstract}
.
Building exceptional user experiences means designing for users of all digital skill level. An increased emphasis on personalization and, with it, adaptive interfaces exacerbates the necessity for digital inclusivity. However, how can designers ensure that they are meeting the needs of those with high and low skillsets? The research reported here employed semi-structured interviews to explore whether the Digital Native Assessment Scale (DNAS) can be used as a tool to classify users and act as a surrogate for predicting their digital profiles. Sixteen participants answered questions about their everyday technology behaviours, as well as their attitudes towards technology. Nine themes emerged through thematic analysis, however only one of these themes was associated with an even, dichotomous split between high scorers on the DNAS and low scorers on the DNAS. Therefore, the DNAS only clearly indicated digital behaviour in a limited number of issues and cannot be relied upon as a proxy for the participant characteristics to be supported in interface design.
\end{abstract}

Keywords: User Experience Design, Participant Selection, Digital Inclusivity.

\section{Introduction}

Understanding users, and building empathy, is a main objective of exceptional user experience design, however this area, like the users themselves, is constantly evolving. Inclusivity, and catering to vastly different digital skillsets, is the driving force behind effective user experiences. This type of personalization is even more relevant with the increased prevalence of machine learning and AI. Different user groups have unique needs and demands that must be met to ensure a sufficiently pleasurable experience.

Two such user groups, digital native and digital immigrant, emerged from Mark Prensky's seminal 2001 paper, "Digital Natives, Digital Immigrants". The concept of 'digital natives,' meaning a person who was raised during the cyber age (Prensky, 2001a), has sparked debate since it was first introduced. While its original ties to age have been largely refuted (Adams \& Pente, 2011; Akçayır, Dündar, \& Akçayır, 2016; Bakla, 2019; Bennett, Maton, \& Lisa Kervin, 2008; Teo, 2013), can the attributes Prensky identifies as the key characteristics of 'digital natives,' growing up with technology, comfort multitasking, reliance on graphics for communication and thriving on instant gratification, be tied to specific attitudes? Furthermore, can understanding these attitudes help designers better design for a wider range of technological skill levels? 
The Digital Native Assessment Scale (DNAS) (Teo, 2013) was developed as a means to identify whether or not an individual was a digital native. While predominantly used in the education sector, there is a potential for use within user centered design. Can the DNAS be used as a tool to identify different levels of digital skills?

This paper reports the parameters of effective user experience design, why they are needed, and how adaptive interfaces are the future of UX. Next, it looks at understanding digital natives and how the digital native assessment scale can be a possible means to evaluate digital skill level. Subsequently, the study methodology is presented. Results from the study are explained, then evaluated in relation to Digital Native Assessment Scale scores. The next section summarizes the findings and highlights the important conclusions. Finally, limitations are discussed, and future work ideas are presented.

\section{Effective User Experiences}

While user experience is present in all technology, there is a stark contrast between effective and ineffective experiences. In order to understand what would make an effective user experience, it is first necessary to understand what user experience is.

The term 'user experience,' or UX, was first introduced by Don Norman to describe the way an individual experiences reality around them (D. A. Norman, 2016). This 'reality' can manifest as how someone interacts with a service, product or device (D. Norman \& Nielsen, n.d.). In 1991, Weiser proclaimed "...the most profound technologies are those that disappear" (Weiser, 1999). This decree is still relevant today, an effective user experience is one that the user does not detect. The antithesis to this is the concept of 'dancing bear' software, where features are so good that users will overlook poor interaction design (Cooper, 1999). However, despite whether a 'dancing bear' software has success, it could be exponentially improved with a good user experience (Cooper, 1999). Ultimately for users, the interaction equates to the system, thus if they are required to exert past their normal effort threshold they will give up (Hartson \& Pyla, 2012). Larry Marine, a leader in UX, concisely explains this concept as "if the user can't use a feature, it effectively does not exist" (Marine in Hartson \& Pyla, 2012). Good user experience is dependent on users being able to access, and use, all features.

Designing for a wide variety of skillsets must be taken into account when designing user experiences. A feature for one user with vast digital expertise may provide an immensely different experience than for one with a limited amount of digital skill. Not only are some hindered by their overall skill, but users have different ability levels across applications and even across the same type of application (Fischer, 2001). Thus, there are multiple avenues in which 'good' user experience has the potential to become obsolete. There have been a variety of avenues proposed to provide an inclusive user experience, with varying degrees of success. One avenue investigated, adaptation of user interfaces to fit with an individual's skill level, has proven to produce higher performance (Benyon, 1993; Trumbly et al, 1993). The increased interest in Machine Learning and, with it, adaptive interfaces, demonstrates the need to develop experiences for multiple eventualities. Many view experts view "AI as the new UI," and thus, adaption as the most important way forward for improving user experience (Brownlee, 2015; Kuang, 2013) 


\subsection{UX, Adaptive Interfaces, and User Testing}

With an adaptive system, it is necessary to design, and conduct user testing, for multiple eventualities. Adaptive user interface systems aim to automatically adjust the interface based on context or demands (Gemmell, Bell, \& Lueder, 2002; Kubat, Holte, \& Matwin, 1998). This is typically driven by user models and, more specifically, user modelling via stereotypes. Modelling via stereotypes is becoming more useful in the European Union due to adoption of the General Data Protection Regulation (GDPR), as this version can generate predictions based on a more limited amount of data (Rich, 1989). These stereotypes can direct the user to experiences aimed at those with a high digital skillset or a low digital skillset. However, these two distinct experiences must be designed and tested to ensure that they achieve the desired interaction. It is paramount for designers to identify participants with the optimum skillset to adequately test these diverse experiences. This study will evaluate if the DNAS can serve as an effective measurement for participant recruitment.

\section{Digital Natives}

Rooted in the contrast of young and old or, more specifically, those born into a world with personal digital technology and those born into a world without, Prensky (2001) presents the terms Digital Native and Digital Immigrant as the new way to describe individuals in the $21^{\text {st }}$ century. Digital Natives are characterized as born on or after 1980, used to receiving information quickly, multi-taskers, graphics driven, thriving on instant gratification, and preferring games to 'serious' work (Prensky, 2001a). Digital Immigrants, on the other hand, were born before the 1980's, turn to new technology second, learn "slowly, step-by-step, one thing at a time, individually, and above all seriously" (Prensky, 2001a). Prensky's first paper focused on the repercussions of this divide on the educational community, as these Digital Natives learn differently to their Digital Immigrant teachers. The second paper (Prensky, 2001b) explained how the brains of Digital Natives are different as they were socialized differently, surrounded by vast amounts of digital input, from a young age.

Despite the two initial papers (Prensky, 2001a, 2001b), and the subsequent additions and critiques (Kennedy, Judd, Churchward, Gray, \& Krause, 2008; Stoerger, 2009; Toledo, 2007) it remains unclear what defines a Digital Native (Akçayır et al, 2016). It seems an "academic moral panic" arose with the introduction of the dichotomy, which presented those who resist the characterizations of Digital Native or Digital Immigrant as out of touch with reality (Bennett et al, 2008). Bennett et al's critique is of the language used in this "moral panic" which they say inhibits debate and gives creditably to unsupported claims.

\subsection{Digital Native Assessment Scale (DNAS)}

The Digital Native Assessment Scale (DNAS) was originally developed as a tool for teachers to understand how their students interacted with, and learned with, technology (Teo, 2013). It is a 21-item questionnaire that measures the degree to which an individual is a Digital Native by asking questions that are associated with Digital Natives. The DNAS uses a 7-point Likert scale that ranges from 'strongly disagree' to 
'strongly agree.' The sum of the results of each of the scale's four factors, (1) growing up with technology, (2) comfortable with multitasking, (3) reliant on graphics for communication, and (4) thriving on instant gratifications and rewards, represents an individual's level of digital nativeness (Teo, 2013). A higher score indicates that the individual is more digitally native. The scale was originally developed with 1018 students in Singapore and has been found to be "statistically valid and reliable" (Teo, 2013). It has since been used in a variety of other Digital Native studies, albeit limited to the education sector (Akçayır et al., 2016; Huang, Teo, \& He, 2019; Teo, 2016; Yong $\&$ Gates, 2014).

Since its creation, the DNAS has served to inform Digital Native literature. However, while the scale is a means of determining if an individual is a Digital Native, it does not demonstrate how this score relates to other factors.

\section{Methodology}

This study comprised of semi-structured interviews with sixteen participants. The participants were drawn from a larger sample of 546 people who had completed an online survey. This survey enabled the DNAS score of each participant to be calculated and also indicated some of the behavioural and attitudinal factors that showed variability across the sample. The latter were used as a starting point for the development of the interview questions, to understand how high and low scorers vary in their technology behaviour.

\subsection{Sampling Criteria}

To be eligible for this study, participants needed to be:

1) Born between 1965-2001

2) A United Kingdom resident, as dictated by the UK immigration criteria

They also needed to take the Digital Natives Assessment Scale questionnaire, to enable their individual score to be generated

\subsection{Recruitment Method}

A purposive sample was recruited based on Digital Native Assessment Scores gathered in the previous online survey. Purposive sampling is used to achieve a sample that has specific characteristics that are important to a study's objectives (Palinkas et al., 2015). This type of sampling is often used in qualitative research, especially in selecting "information-rich cases" to best utilize limited resources (Palinkas et al., 2015; Patton, 2002). It is necessary as the aim of the interviews is to understand and make sense of certain people's lived experiences, not to be a representation of all people (Gill, 2005).

Figures 1 to 3 show the rationale for the selection of participants. Figure 1 shows the range of scores based on the original DNAS scale (Teo, 2013). Figure 2 shows the range of DNAS scores for the online survey sample from which the interview participants were drawn. The survey sample only included one participant with 'low' scores, the reason may have been tied to the fact that it was an online survey. As the sample for the interviews was drawn from this wider sample, a 'constructed low' of between 84 and 117 was used, along with a 'constructed high' of between 183 and 206. Eight 'high DNAS' participants were recruited along with eight 'low DNAS' participants. 
DNAS SCALE $_{(2013)}$

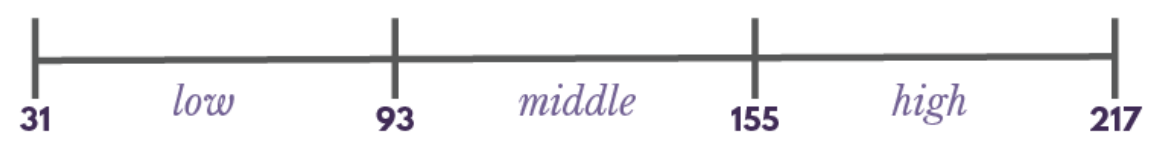

Figure 1: Digital Native Assessment Scale Spread

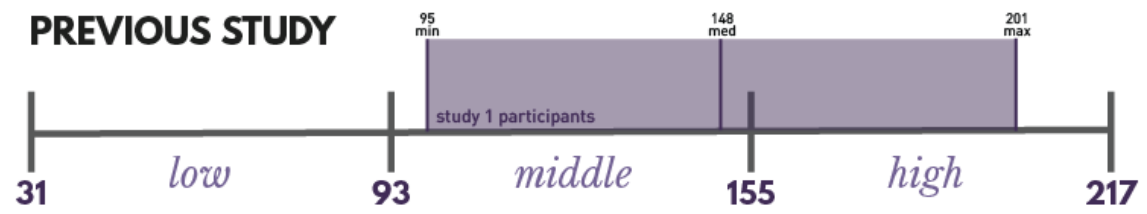

Figure 2: Previous Study

\section{CURRENT STUDY}

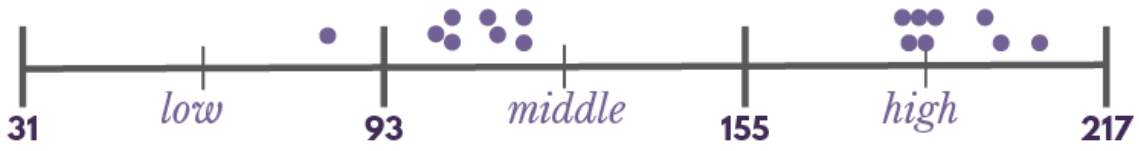

Figure 3: Participants in Current Study

The Table below presents the different individuals that participated in this study, along with their DNAS scores, age, and self-reported gender.

Table 1. Participant Table

\begin{tabular}{llll}
\hline $\begin{array}{l}\text { Participant } \\
\text { Number }\end{array}$ & Age & DNAS Score & Sex \\
\hline P1 & 27 & 182 & $\mathrm{~F}$ \\
P2 & 31 & 117 & $\mathrm{~F}$ \\
P3 & 38 & 107 & $\mathrm{M}$ \\
P4 & 42 & 107 & $\mathrm{~F}$ \\
P5 & 47 & 183 & $\mathrm{M}$ \\
P6 & 42 & 117 & $\mathrm{~F}$ \\
P7 & 25 & 197 & $\mathrm{~F}$ \\
P8 & 25 & 187 & $\mathrm{~F}$ \\
P9 & 25 & 206 & $\mathrm{M}$ \\
P10 & 24 & 114 & $\mathrm{M}$ \\
P11 & 26 & 195 & $\mathrm{~F}$ \\
P12 & 50 & 184 & $\mathrm{M}$ \\
P13 & 35 & 186 & $\mathrm{M}$ \\
P14 & 28 & 84 & $\mathrm{~F}$ \\
P15 & 31 & 115 & $\mathrm{M}$ \\
P16 & 36 & 105 & $\mathrm{M}$ \\
\hline
\end{tabular}


The interviews were conducted in Loughborough, Coventry, Glasgow and Derby. They were captured on a voice recorder, then fully transcribed by the researcher. All interviews fully complied with Loughborough University's ethics procedures.

\subsection{Design of Semi-Structured Interviews}

To generate questions for interviews, it was important that the researcher investigate the background research fully. From here, it was necessary to develop a list of key topics that the questions were based upon. While some moderators can go into an interview scenario with only a list of themes, as these were semi-structured interviews, the researcher had a list of questions to provide a framework for the interview and guide it along. The questions developed to provide a framework were designed to stimulate information that is "factual', descriptive, thoughtful, emotional, or affectual" (Gill, 2005). One of the main benefits of semi-structured interviews over structured interviews is the ability to adjust wording and order to best suit the participant (Bryman, 2012). This deviation of question order can be done in semi-structured interviews for the purpose of exploring interesting areas and topics that might arise during the interview. While new questions may be aggregated in the moment, generally all the questions in the question list will be asked and in a similar wording (Bryman, 2012).

The interviews comprised a core set of 24 open ended questions, with additional prompts and follow ups included on a case-by-case basis to facilitate clarification or expanding on answers. The topics covered by these questions were based on the results from the previous online survey. As these were semi-structured interviews, the number of questions posed varied depending on how the participant answered. Questions were added or adjusted based on the participant's response to previous questions.

\subsection{Recording and Transcription}

Recording and transcription serve as important steps in the understanding and analysis process. In order to fully immerse in the interview, audio recording is implemented as a key tool. This allows the researcher to focus on interactions rather than the pressure to put into writing every word of the conversation (Gill, 2005). In addition to this, recording provides a more accurate record of the conversation, and the nuances, than relying on written notes (Gill, 2005). However, the greatest benefit is the allowing the researcher to listen to the conversation over and identify ideas that might have been missed during the initial conversation (Gill, 2005).

After each interview, the audio recording was transcribed by the primary researcher. The transcription process occurred as follows: audio was assessed for quality by listening to each recording and then was inputted into NVivo 12 (NVIVO, 2020) transcribed, and timestamped (Welsh, 2002). This system makes it easier to compare transcribed data with the original audio, maintaining the transcription's validity (Kvale \& Brinkmann, 2009). While transcription can take time, it allows for a re-familiarisation which can aid in data analysis (Crang \& Cook, 2012). NVivo 12 software was used as it can manage a large amount of different types of data, as well as serving as a powerful tool for analysis. Codes can easily be assigned and modified, if needed, to create more efficient analysis, as well as providing data visualizations for a clear overall understanding. Welsh (2002) elucidates that software such as NVivo "serves to facilitate an accurate and transparent data analysis process whilst also 
providing a quick and simple way of counting who said what and when, which in turn, provides a reliable, general picture of the data."

\subsection{Data Analysis}

Aided by NVivo, an in-depth thematic analysis was conducted on the responses from the interview. Thematic analysis is the method best suited to analyse semi-structured interviews. It is defined as: "A method for identifying, analyzing, and reporting patterns (themes) within data. It minimally organizes and describes your data set in (rich) detail. However, frequently it goes further than this, and interprets various aspects of the research topic" (Braun \& Clarke, 2006).

Themes are "specific patterns of meaning found in the data," and can contain manifest content or latent content (Joffe, 2011). Manifest content refers to explicit mentions of an idea or phenomenon, whereas latent content provides implicit references (Joffe, 2011).

The data analysis was carried out following the 'phases of thematic analysis' (Table 1) that were identified by Braun and Clark (2006).

Table 2. Phases of thematic analysis (Braun \& Clark, 2006).

\begin{tabular}{|c|c|c|}
\hline Phase & & Description of the process \\
\hline 1 & $\begin{array}{l}\text { Familiarizing yourself with } \\
\text { your data }\end{array}$ & $\begin{array}{l}\text { Transcribing data if needed, reading and re- } \\
\text { reading data, noting down initial ideas }\end{array}$ \\
\hline 2 & Generate initial codes & $\begin{array}{l}\text { Coding interesting features found in the data in a } \\
\text { systematic way across the entire set of data, then } \\
\text { collating data relevant to each code }\end{array}$ \\
\hline 3 & Searching for themes & $\begin{array}{l}\text { Assembling codes into potential themes, then } \\
\text { gathering data relevant to each probable theme }\end{array}$ \\
\hline 4 & Reviewing themes & $\begin{array}{l}\text { Checking if the themes work in relation to the } \\
\text { coded extracts and the entire set of data, then } \\
\text { generating a thematic map of the analysis }\end{array}$ \\
\hline 5 & $\begin{array}{l}\text { Defining and naming } \\
\text { themes }\end{array}$ & $\begin{array}{l}\text { Ongoing analysis to refine the details of the } \\
\text { themes, as well as the narrative the data tells, } \\
\text { producing clear definitions and names for each } \\
\text { theme }\end{array}$ \\
\hline 6 & Producing report & $\begin{array}{l}\text { The last opportunity for analysis. Selecting } \\
\text { compelling examples, final analysis of selected } \\
\text { examples, relating the analysis back to the } \\
\text { research questions and wider literature, producing } \\
\text { a scholarly report of the analysis }\end{array}$ \\
\hline
\end{tabular}

These themes were then evaluated against the DNAS scores of the participants in each theme to understand how the digital behaviours and the scores related. 


\section{$5 \quad$ Results \& Discussion}

Using thematic analysis, 9 overarching themes relating to how individuals behave with technology were identified: (1) Attitudes, (2) Social Influence, (3) Tool, (4) Convenience, (5) Extension of Self, (6) Propinquity, (7) Awareness, (8) Connection, and (9) Consistency. The following sections explain each theme in turn, with a discussion of whether it showed a relationship with participants' score on the DNAS scale.

\subsection{Attitudes}

Certain attitudes, or emotions, are identified as most prevalent when discussing technological behaviours. Participants exhibit strong inclinations towards different actions in using smartphones and smart assistants. Confidence, trust, anxiety and curiosity portray different facets of users' feelings towards the devices that they own. However, this behaviour did not demonstrate a dichotomous relationship with DNAS score.

\section{$5.2 \quad$ Society}

Social norms dictate what is appropriate in society. These rules can vary among cultures, as well as between individual people. Rules around technology can be even more nuanced (Tene \& Polonetsky, 2013). While individuals have their own set of rules for when it is appropriate to use their phones, the ambiguity of these rules is prevalent. Participant in this theme did not favor a behaviour based on their DNAS score.

\subsection{Tool}

A large number of participants see technology as a tool to use to achieve their goals, however the emotion attached to this tool differed. Some participants regarded their technology with no emotional attachment, that it is simply a vessel for information. However, these differences were not divided by DNAS score.

\subsection{Convenience}

In this theme, participants prioritized making things easier for themselves by optimizing their technology. Overall, the push for convenience was driven by three different mindsets: utilitarian with a lack of emotion, increasing speed of actions, or to bolster muscle memory. While the three mindsets may have slightly leaned towards one end of the DNAS scores, the relationship was not strong or direct. 


\subsection{Extension of self}

Technology is seen by some participants as an extension of the self, both physically and metaphorically. The notion that the phone has replaced the phonebook and the need to memorize phone numbers encapsulates this idea. Participants range from not caring at all to demonstrating heavily reliance on technology. Most of the individuals that make up this theme are in the high DNAS group, however there were a few on this theme from the low DNAS group.

\subsection{Propinquity}

Propinquity can be defined as the 'state of being close to something or someone' (OED, 2020). In this instance, propinquity relates to how users interact with technology and those they are closest with, either by relation or by housing situation. Elements such as family, house rules, and sharing devices arise as avenues of interest. Attitudes and behaviours exhibited in Propinquity did not strongly indicate towards one end of the DNAS scale.

\section{$5.7 \quad$ Awareness}

While some participants do not reflect on their technology use, and how it could negatively affect them, others are very aware of the role technology plays in their lives. This understanding, and how it does or not affect behavior, is important to note as it relates to a person's aspirations and motivations. An even number of high and low were presented in this theme.

\subsection{Connection}

Participants articulate that the reality of constant connection is met with either strong positive or negative emotions. Technology can serve to keep individuals connected, especially when they are physically distanced. Participants who are partial to the connectivity benefits of technology, highlight the ease of staying in touch with those far away as a top benefit. The current minimum expectation is that connection is always available, thus frustration occurs when this threshold is not reached. Though many see connection as a benefit to their lives, there are some see the perpetual availability as too much pressure and prefer a more limited connectivity. This was the only theme with a clear, dichotomous split between behaviours. Participants with high scores on the DNAS favoured constant connectivity and those with low scores preferred constrained connection.

\subsection{Consistency}

Uniformity among the same type of device, such as smartphones, emerges as an important value for some participants. Users are particular about how their devices should be ordered and structured. Even when updating devices, participants expect their 
technology to stay consistent. These behaviours and expectations have no tie to either high or low DNAS scorers.

\section{Conclusion}

Results suggest that the DNAS is not a completely accurate indicator of any specific attitude or behavior, as most themes had a varied combination of high and low level DNAS participants. The only theme in which behaviors are split by DNAS group is Connection, with high scoring individuals highlighting constant connection as a priority and low scoring individuals seeing the same connection as a negative effect of technology.

This is important for practitioners to consider when designing for a variety of user groups, especially those with different levels of technological competence. While levels of connectivity may be more closely associated with the dichotomy of DNAS scores, the majority of attitudes and behaviours towards technology are not linked to a particular set of scores. This research demonstrates that DNAS score alone cannot be relied upon to define user groups for adaptive interfaces, thus it is not an effective tool for characterising participants in user experience design.

Future research could further explore the nine themes in order to understand how individuals vary according to the themes, whether clusters of themes can be used to create personas, and how this understanding can be used to improve user experience in system design.

Acknowledgements. The research reported in this paper was conducted as part of a $\mathrm{PhD}$ studentship at Loughborough University funded by Jaguar Land Rover.

\section{References}

Adams, C. A., \& Pente, P. (2011). Teachers teaching in the new mediascape: Digital immigrants or "natural born cyborgs"? E-Learning and Digital Media, 8(3), 247-257. https://doi.org/10.2304/elea.2011.8.3.247

Akçayır, M., Dündar, H., \& Akçayır, G. (2016). What makes you a digital native? Is it enough to be born after 1980? Computers in Human Behavior, 60, 435-440. https://doi.org/10.1016/J.CHB.2016.02.089

Bakla, A. (2019). A Study of Digital Nativeness and Digital Productivity: Data from EFL and ESL Contexts. Malaysian Online Journal of Educational Technology, 7(1). https://doi.org/10.17220/mojet.2019.01.002

Bennett, S., Maton, K., \& Lisa Kervin. (2008). The "digital natives" debate: A critical review of the evidence. British Journal of Educational Technology, 39(5), 775-786. https://doi.org/10.1111/j.1467-8535.2007.00742.x

Braun, V., \& Clarke, V. (2006). Using thematic analysis in psychology. Qualitative Research in Psychology. https://doi.org/10.1191/1478088706qp063oa

Brownlee, J. (2015). Apple Finally Learns AI Is The New UI. Co.Design. Retrieved from https://www.fastcompany.com/3047199/apple-finally-learns-ai-is-the-new-ui

Bryman, A. (2012). Social research methods Bryman. OXFORD University Press. https://doi.org/10.1017/CBO9781107415324.004

Buy NVivo Now | NVivo. (n.d.). Retrieved February 16, 2020, from https://www.qsrinternational.com/nvivo/nvivo-products/nvivo-12-plus 
Cooper, A. (1999). The Inmates Are Running the Asylum: Why High Tech Products Drive Us Crazy and How to Restore the Sanity. The Inmates are Running the Asylum Why High Tech Products Drive us Crazy and How to Restore the Sanity.

Crang, M., \& Cook, I. (2012). Doing Ethnographies. Doing Ethnographies. https://doi.org/10.4135/9781849208949

Gemmell, J., Bell, G., \& Lueder, R. (2002). Adaptive Interfaces for Ubiquitous Web Access. Communications of the ACM, 45(5), 34-38. Retrieved from https://dl.acm.org/doi/fullHtml/10.1145/506218.506240

Gill, V. (2005). Tell me about . . . : using interviews as a research methodology. In Methods in Human GeographyHUMAN GEOGRAPHY A guide for students doing a research project.

Hartson, R., \& Pyla, P. S. (2012). The UX Book: Process and Guidelines for Ensuring a Quality User Experience. The UX Book: Process and Guidelines for Ensuring a Quality User Experience. https://doi.org/10.1016/C2010-0-66326-7

Huang, F., Teo, T., \& He, J. (2019). Digital nativity of university teachers in China: factor structure and measurement invariance of the Digital Native Assessment Scale (DNAS). Interactive Learning Environments, 1-15. https://doi.org/10.1080/10494820.2019.1570278

Joffe, H. (2011). Thematic Analysis. In Qualitative Research Methods in Mental Health and Psychotherapy: A Guide for Students and Practitioners. https://doi.org/10.1002/9781119973249.ch15

Kennedy, G. E., Judd, T. S., Churchward, A., Gray, K., \& Krause, K.-L. (2008). First year students' experiences with technology: Are they really digital natives? Australasian Journal of Educational Technology, 24(1), 108-122. Retrieved from http://citeseerx.ist.psu.edu/viewdoc/download?doi=10.1.1.85.9526\&rep=rep1\&type=pdf

Kuang, C. (2013). Why a New Golden Age for UI Design Is Around the Corner. Retrieved June 4, 2020, from https://www.wired.com/2013/08/design-and-the-digital-world/

Kubat, M., Holte, R. C., \& Matwin, S. (1998). Machine learning for the detection of oil spills in satellite radar images. Machine Learning, 30(2-3), 195-215. https://doi.org/10.1023/A:1007452223027

Kvale, S., \& Brinkmann, S. (2009). Learning the Craft of Qualitative Research Interviewing. In InterViews: learning the craft of qualitative research interviewing.

Norman, D. A. (2016). Don Norman on the term "UX" (Video). Retrieved June 5, 2020, from https://www.nngroup.com/videos/don-norman-term-ux/

Norman, D., \& Nielsen, J. (n.d.). The Definition of User Experience (UX). Retrieved June 5, 2020, from https://www.nngroup.com/articles/definition-user-experience/

Palinkas, L. A., Horwitz, S. M., Green, C. A., Wisdom, J. P., Duan, N., \& Hoagwood, K. (2015). Purposeful Sampling for Qualitative Data Collection and Analysis in Mixed Method Implementation Research. Administration and Policy in Mental Health and Mental Health Services Research. https://doi.org/10.1007/s10488-013-0528-y

Patton, M. Q. (2002). Qualitative research and evaluation methods. Qualitative Inquiry. https://doi.org/10.2307/330063

Prensky, M. (2001a). Digital Natives, Digital Immigrants Part 1. On the Horizon, 9(5), 1-6. https://doi.org/10.1108/10748120110424816

Prensky, M. (2001b). Digital Natives, Digital Immigrants Part 2: Do They Really Think Differently? On the Horizon, 9(6), 1-6. https://doi.org/10.1108/10748120110424843

Propinquity | Definition of Propinquity by Oxford Dictionary on Lexico.com also meaning of Propinquity. (n.d.). Retrieved June 5, 2020, from https://www.lexico.com/en/definition/propinquity

Stoerger, S. (2009). The digital melting pot: Bridging the digital native-immigrat divide. First Monday, 14(7), 1-9. Retrieved from http://firstmonday.org/htbin/cgiwrap/bin/ojs/index.php/fm/issue/view/292

Tene, O., \& Polonetsky, J. (2013). A Theory of Creepy: Technology, Privacy and Shifting Social Norms. Yale Journal of Law and Technology, 16. Retrieved from 
https://heinonline.org/HOL/Page?handle=hein.journals/yjolt16\&id=59\&div=\&collection $=$

Teo, T. (2013). An initial development and validation of a Digital Natives Assessment Scale (DNAS). Computers \& Education, 67, 51-57. https://doi.org/10.1016/j.compedu.2013.02.012

Teo, T. (2016). Do digital natives differ by computer self-efficacy and experience? An empirical study. Interactive Learning Environments, 24(7), 1725-1739. https://doi.org/10.1080/10494820.2015.1041408

Toledo, C. A. (2007). Digital Culture: Immigrants and Tourists Responding to the Natives' Drumbeat. International Journal of Teaching and Learning in Higher Education, 19(1), 84-92. Retrieved from http://www.isetl.org/ijtlhe/

Weiser, M. (1999). The computer for the 21 st century. ACM SIGMOBILE Mobile Computing and Communications Review, 3(3), 3-11. https://doi.org/10.1145/329124.329126

Welsh, E. (2002). Dealing with data: Using NVivo in the qualitative data analysis process. Forum Qualitative Sozialforschung. https://doi.org/10.17169/fqs-3.2.865

Yong, S.-T., \& Gates, P. (2014). Born Digital: Are They Really Digital Natives? International Journal of E-Education, e-Business, e-Management and e-Learning, 4(2), 2-5. https://doi.org/10.7763/ijeeee.2014.v4.311 